\title{
Rare Side Effects of Propofol Administration-Case Report and a Brief Literature Review
}

\author{
Ersin Ismail ${ }^{1}$, Plamen Dimitrov ${ }^{2}$, Dimana Mitsova ${ }^{1}$, Svetoslav Dobrev ${ }^{1}$, Snezhana Stancheva ${ }^{1}$ and Natasha $^{2}$ \\ Ivanova $^{3}$ \\ 1. Faculty of Medicine, Medical University of Varna, Varna 9010, Bulgaria \\ 2. Anesthesiology and Reanimation, Balchik Hospital, Balchik 9600, Bulgaria \\ 3. Faculty of Pharmacy, Medical University of Varna, Varna 9010, Bulgaria
}

\begin{abstract}
Introduction: Propofol is an intravenous general anesthetic and sedation drug for use in the induction and maintenance of anesthesia or sedation. It is included in WHO Model List of Essential medicines and approved by the FDA (food and drug administration) in 1989. The side effects of Propofol have been studied widely in the last 25 years. They can be easily managed and that is why Propofol has become a first choice drug for the most of the anesthesiologists worldwide. This paper presents a case report of Propofol induced pulmonary edema and also a review of some of the rarest and unusual manifestations of Propofol side effects. Some of them are urine discoloration, tissue necrosis, rhabdomyolysis and postoperative pancreatitis. Methods and materials: A case summary of 18-years old woman with unusual postoperative pulmonary reaction was considered along with other documented cases. Several full-text articles were briefly analyzed for estimating the role of Propofol for a number of strange and potentially life threatening conditions. Results: Despite the low incidence rate, the presented case could be determined as a pulmonary edema due to its clinical features. Furthermore, rare drug reactions such as rhabdomyolysis, tissue necrosis, postoperative pancreatitis etc. may remain unrecognized and create diagnostic and therapeutic issues. Conclusions: Although the officially reported dangerous reaction, Propofol remains one of the best hypnotic and sedative agents. The better knowledge of the full list of drug reactions considered as rare and very rare is a guarantee of an adequate and a better therapeutic behavior.
\end{abstract}

Key words: Propofol, pulmonary edema, urine discoloration, tissue necrosis, rhabdomiolysis, postoperative pancreatitis.

\section{Introduction}

Propofol (2,6-diisopropylphenol) is an ultrashort-acting intravenous hypnotic and sedative agent formulated as an emulsion. It contains soybean oil, egg phospholipid, and glycerol [1, 2]. Propofol was approved by the Bulgarian Drug Agency in 2006 and has been used for almost 10 years by anesthesiologists in the country. The successful therapeutic approach of frequent drug reactions such as hypotension, respiratory depression, brady- or tachycardia, etc. makes it a first choice medicine in surgical interventions, regardless of their duration. However, rare drug reactions remain a challenge for the anesthesiology teams, because they lead to

Corresponding author: Ersin Ismail, Medical student, research fields: anesthesiology, oncology, tropical medicine. unpredictable consequences for the patient. Some of them are harmless, such as discoloration of urine, others cause local damages-tissue necrosis. There are also some complications that directly endanger the patient's life. This group includes rhabdomyolysis, acute pancreatitis and acute pulmonary edema. Noncardiogenic pulmonary edema after administration of Propofol is an extremely rare complication. As far as we know, the clinical case presented by us is the first one reported in Bulgaria.

\section{Case Report}

18-years-old woman presented in the ED with vomiting and a moderate abdominal pain. Antiemetics were prescribed and she was sent home but not so long after that she was admitted to a surgical department with abdominal pain localized at the mesogastrium. 
After consultation with the doctor on duty, she was scheduled for a routine appendectomy. The medical history was clean, without any concomitant diseases or drug allergies. The routine initial laboratory workup was unremarkable. The moderate leukocytosis was an expected finding but nothing unusual was detected in the blood count, electrolytes, renal and liver function panel. She had a Mallampatti score of 1 , no previous surgical interventions, nonsmoker.

The patient received $1 \mathrm{~g}$ Ceftriaxone preoperatively. Induction of anesthesia was accomplished with $30 \mathrm{mg}$ Atracurium, $0.1 \mathrm{mg}$ Fentanyl and $180 \mathrm{mg}$ Propofol. To facilitate tracheal intubation, $100 \mathrm{mg}$ Succinylcholine was administered. Sevoflurane was used to maintain the anesthesia.

The appendectomy lasted 60 minutes with no intraoperative complications. The patient was extubated, fully awake and oriented. The saturation was $96 \%$ on room air. About 10 minutes later, hypoxemia $\left(\mathrm{SaO}_{2}\right.$ 72\%), tachycardia and central cyanosis occurred. The consultation with a pulmonologist revealed bilateral coarse crackles throughout both lung fields with normal heart sounds. Body temperature was $36.8^{\circ} \mathrm{C}$, heart rate 88 beats $/ \mathrm{min}$, blood pressure-109/67 mmHg, respirations 22 breaths $/ \mathrm{min}$. She developed the clinical picture of acute pulmonary edema.

With an oxygen mask the saturation rose and remained 90\%. The anesthesiologist launched transporting the patient to a hospital with an intensive care unit. The treatment included Furosemide $40 \mathrm{mg}$ for every 6 hours and Digoxin $0.125 \mathrm{mg}$ per day. It was intended to reduce the transudate in order to overcome the hypoxemia. The patient tolerated the treatment unremarkable and no coarse crackles were auscultated in Day 3. Follow-up chest X-ray 5 days after admission showed a resolution of lung infiltration. The treatment goal was achieved without any additional medications and approaches. No other complications were present and the patient was discharged from the hospital in a stable, asymptomatic condition.

\section{Discussion}

There are no other etiological links between the clinical case we reported and the case reports of other colleagues. People with no history of cardiovascular and other diseases develop acute pulmonary edema after application of Propofol—during or mostly after the surgical intervention.

Two main types of pulmonary edema are recognized—cardiogenic (or hydrostatic)—a result from an elevated pulmonary capillary pressure from left-sided heart failure and noncardiogenic (increased permeability)—from injury of the endothelial and (usually) epithelial barriers [3]. Our patient was preoperatively consulted with a cardiologist and no abnormalities were found in ECG and physical examination. The family history did not show cardiovascular events on early age. Also, no other member of the family has presented any unusual reactions during surgical interventions or a specific drug reaction.

Previous reports of anesthesia-induced pulmonary edema have been associated with airway obstruction, gas embolism, cardiac failure, fluid overload, acid aspiration, reactions to blood products, and a drug hypersensitivity reaction [4-8]. All of these were excluded. Based on the clinical findings and references to literary sources we believe that the case we describe is an example of a Propofol-induced pulmonary edema. Our case confirms that this reaction is not dose-dependent or age-dependent. Regional nerve block could not be considered because the intervention is in the abdominal cavity. The proper clinical signs and a multidisciplinary approach have provided the opportunity for a favorable outcome of this acute condition.

Some of the clinical characteristics are demonstrated in the Table $1[1,5,9,10]$. The age of the patients varies between 10 months and 61 years, doses $40-400 \mathrm{mg}$ and the time of onset $-30-70$ minutes. Comorbidities are rare and do not affect the therapeutic approaches and the time of clinical resolution-within 5 days. Diuretics 
Table 1 Brief characteristics of clinical presentations of 6 pulmonary edema case reports.

\begin{tabular}{|l|l|l|l|l|l|l|}
\hline Variables/ Authors & Tsai [4] & Tsutsumi [9] & Inal [10] & Tai [5] & Waheed [1] & Ismail, Dimitrov \\
\hline Age and gender & $35, \mathrm{M}$ & $61, \mathrm{~F}$ & $35, \mathrm{~F}$ & 10 month, M & 23, M & $18, \mathrm{~F}$ \\
\hline Comorbidities & $\begin{array}{l}\text { Nasopharyngeal } \\
\text { cancer }\end{array}$ & Hypertension & None & Not reported & None & None \\
\hline $\begin{array}{l}\text { Total Propofol dose } \\
\text { (mg) }\end{array}$ & 400 & 80 & 300 & 40 & 350 & 180 \\
\hline Time to onset & 60 min & Not reported & 45 min & $30-45$ min & 60 min & 70 min \\
\hline $\begin{array}{l}\text { Key clinical } \\
\text { manifestations }\end{array}$ & $\begin{array}{l}\text { Hypoxemia, } \\
\text { hypotension }\end{array}$ & Hypoxemia & $\begin{array}{l}\text { Hypoxemia, } \\
\text { hypotension }\end{array}$ & $\begin{array}{l}\text { Hypoxemia, tachypnea, } \\
\text { hypotension, bradycadia, } \\
\text { skin rash }\end{array}$ & $\begin{array}{l}\text { Hypoxemia, } \\
\text { cough }\end{array}$ & $\begin{array}{l}\text { Hypoxemia, } \\
\text { tachycardia }\end{array}$ \\
\hline $\begin{array}{l}\text { Pharmacological } \\
\text { interventions }\end{array}$ & $\begin{array}{l}\text { Steroids, dopamine, } \\
\text { epinephrine }\end{array}$ & Diuretics & Not reported & Epinephrine & $\begin{array}{l}\text { Diuretics, } \\
\text { antibiotics }\end{array}$ & Diuretics \\
\hline $\begin{array}{l}\text { Time to clinical } \\
\text { resolution }\end{array}$ & 5 days & 4 days & Not reported & 9 hours & 2 days & 5 days \\
\hline
\end{tabular}

and epinephrine are the most commonly used medications.

This complication remains pathogenetically unclear but anaphylactoid reaction is the most frequently postulated etiology [11]. It is considered that both diisopropyl chain and phenol group have the potential to cause allergic reaction [5].

\section{Other Rare Side Effects}

Urine discoloration. Discoloration of the urine may indicate the presence of an underlying systemic disorder. It is not unique to Propofol. Other potential causes include Cimetidine, Promethazine, Amitriptyline, Indomethacin, Metoclopramide etc. [12, 13]. The green urine color due to Propofol is thought to be a result of its phenolic green metabolite produced in the liver and excreted in the urine. Standard urine analysis and urine cultures remain unremarkable [14-17]. This drug reaction is dose-dependent and usually appears after a continuous infusion of Propofol. However in very rare cases single Propofol infusion during anesthesia is enough to cause urine discoloration [12]. Although green urine associated with Propofol is benign and rare, prompt recognition of such side effects is important in limiting expenditures, inordinating drug exposure, and distressing among patients and clinicians [14, 15].

Rhabdomyolysis. Rhabdomyolysis is a clinical entity that evolves after skeletal injury. The symptoms and signs are secondary to muscle injury and to the effects of the release of toxic intracellular contents [18]. Drug-induced rhabdomyolysis has been reported as resulting from many possible agents, including the use of Propofol for sedation of children in the intensive care unit [18-21]. Current recommendations suggest a dosage less than $8 \mathrm{mg} / \mathrm{kg} / \mathrm{h}$ and an application not longer than 2 days in adults. On molecular level Propofol is toxic for mitochondria and elevates the malonyl-carnitine levels. It uncouples the oxidative phosphorylation, inhibits the respiratory chain at complex II and most probably also at complex IV on the level of cytochrome oxidase activity [22]. Clinically, an elevation of creatine kinase is observed, followed by myopathy and rhabdomyolysis which leads to acute kidney failure. The absence of a body temperature above $40{ }^{\circ} \mathrm{C}$ precludes the possibility of malignant hyperthermia. Both skeletal and cardiac muscle degradation are discovered on autopsy [18, 22, 23].

Tissue necrosis. Extravasation injuries due to Propofol are relatively rare, though cases of tissue necrosis have been reported [24]. They are a result from a combination of factors, including solution cytotoxicity, osmolality, vasoconstrictor properties, infusion pressure, regional anatomical peculiarities, and other patient factors [25, 26]. This complication results from a failure to provide intravenous access or from an extravasation due to improper insertion of the 
IV cannula. The affected area shows signs of inflammation-it is red, swollen, warm and painful. Despite the presence of very few cases of tissue necrosis, every wound at the side of infusion should arouse a suspicion of an extravasation injury [25].

Acute pancreatitis. Pancreatitis is a common disease with an obscure pathogenesis and an unpredictable outcome. Gallstones and alcohol constitute $80 \%$ of all cases. A possible pathogenesis of pancreatitis secondary to Propofol can only be speculated. Many authors discuss the link between hypertriglyceridemia as a frequent consequence of prolonged Propofol usage and pancreatitis [26]. However, excluding the risk factors of primary disease, several case reports present the development of postoperative pancreatitis. In patients who experience abdominal symptoms after Propofol administration, pancreatitis should be considered as a possible cause and an appropriate diagnostic testing should be performed [26-29].

\section{Conclusions}

Propofol is widely used in the anesthesia practice-from complicated operations to micro-or non-invasive procedures owning to the acceptable price and the pharmacological benefits. Rare side effects are often neglected and most of the specialists remain unprepared for them. Most of the published case reports follow the successful therapeutic approaches and that is why we consider that actually a high number of the rare complications have severe consequences.

\section{References}

[1] Waheed, M., and Oud, L. 2014. “Acute Pulmonary Edema Associated with Propofol: An Unusual Complication.” West J Emerg Med. 15 (7): 845-8.

[2] Marik, P. E. 2004. "Propofol: Therapeutic Indications and Side-effects.” Curr Pharm Des. 10: 3639-49.

[3] Murray, J. F. 2011. "Pulmonary edema: pathophysiology and diagnosis.” Int J Tuberc Lung Dis. 15 (2): 155-60.

[4] Tai, Y., Yao, C., and Yang, Y. 2003. “Acute Pulmonary Edema after Intravenous Propofol Sedation for Endoscopy in a Child.” 37:320-2.

[5] Tsai, M. H., Kuo, P. H., Hong, R. L., et al. 2001.
"Anaphylaxis after Propofol Infusion for Port-A-Cath Insertion in a 35-year Old Man." J Formos Med Assoc. 100: 424-6.

[6] Fredrick, O., and Howard, E. H. 1971. "Pulmonary Edema during Anesthesia.” Anesthesiology 34:102-3

[7] Fisher, M. M., and Stevenson, I. F. 1986. "Unexplained Acute Membrane Pulmonary Edema Related to Anesthesia.” Anaesth Intensive Care 14: 29-31.

[8] Stoelting, R. K. 1970. "Acute Pulmonary Edema during Anesthesia and Operation in a Healthy Young Patient.” Anesthesiology 33: 366-9.

[9] Tsutsumi, N., Tohdoh, Y., Kawana, S., et al. 2001. “A Case of Pulmonary Edema after Electroconvulsive Therapy under Propofol Anesthesia.” Masui (Jpn J Anesthesiol) 50: 525-7.

[10] Inal, M. T., Memis, D., Vatan, I., et al. 2008. "Late Onset Pulmonary Edema Due to Propofol.” Acta Anesthesiol Scand. 52: 1015-7.

[11] Laxenaire, M. C., Mata-Bermejo, E., Moneret-Vautrin, D. A., et al. 1992. "Life-threatening Anaphylactoid Reactions to Propofol.” Anesthesiology 78: 604-9.

[12] Gupta, D., and Gupta, R. 2011. “Green Urine.” The Scientific World Journal 11: 1101-2.

[13] Gillett, M. J., and Burnett, J. R. 2006. "Medications and Green Urine.” Intern. Med. J. 36: 64-6.

[14] Lee, J. S., Jang, H. S., and Park, B. J. 2013. “Green Discoloration of Urine after Propofol Infusion.” Korean $J$ Anesthesiol. 65 (2): 177-9.

[15] Blakey, S. A., Hixson-Wallace, J. A. 2000. "Clinical Significance of Rare and Benign Side Effects: Propofol and Green Urine.” Pharmacotherapy 20: 1120-2.

[16] Bodenham, A., Culank, L. S., and Park, G. R. 1987. "Propofol Infusion and Green Urine.” Lancet 2: 740.

[17] Callander, C. C., Thomas, J. S., and Evans, C. J. 1989. "Propofol and the Colour Green." Anaesthesia 44: 82.

[18] Stelow, E. B., Johari, V. P., Smith, S. A., Crosson, J. T., and Apple, F. S. 2000. "Propofol-associated Rhabdomyolysis with Cardiac Involvement in Adults: Chemical and Anatomic Findings.” Clin Chem. 46 (4): 577-81.

[19] Carry, S. C., Chang, D., and Connor, D. "Drug- and Toxin-induced Rhabdomyolysis.” Ann Emerg. Med. 18: 1068-94.

[20] Hanna, J. P., and Ramundo, M. L. 1998. "Rhabdomyolysis and Hypoxia Associated with Prolonged Propofol Infusion in Children.” Neurology 50: 301-3.

[21] Neff, S. P. W., Futter, M. E., and Anderson, B. J. 1997. "Fatal Outcome after Propofol Sedation in Children." Anaesth Intensive Care 25: 581-2.

[22] Hohenegger, M. 2012. "Drug Induced Rhabdomyolysis." Curr Opin Pharmacol. 12 (3): 335-9. 
[23] Zhou, Z. B., Yang, X. Y., Zhou, X., Niu, L. J., Xiao, L. C., Huang, W. Q., and Feng, X. 2015. "Propofol-induced Rhabdomyolysis: A Case Report.” Int J Clin Pharmacol Ther. 53 (10): 890-4.

[24] Sharma, R., Yoshikawa, H., et al. 2012. "Chemical Burn Secondary to Propofol Extravasation.” West J Emerg Med. 13 (1): 121-2.

[25] Basak, P., Poste, J., and Jesmajian, S. 2012. "Propofol Extravasation and Tissue Necrosis.” Indian J Dermatol. 57 (1): 78-9.

[26] Dolin, S. J. 2000. “Drugs and pharmacology.” In Total
Intravenous Anesthesia, edited by Padfield, N. L. Oxford: Butterworth Heinemann, 13-35.

[27] Scholten, J. G., and Buijs, E. 2014. “Acute Pancreatitis after Propofol Administration.” Ned Tijdschr Geneeskd 158: A7115.

[28] Gottschling, S., Larsen, R., Meyer, S., Graf, N., and Reinhard, H. 2005. "Acute Pancreatitis Induced by Short-term Propofol Administration.” Paediatr Anaesth 15 (11): 1006-8.

[29] Steinberg, W., and Tenner, S. 1994. “Acute Pancreatitis.” N. Engl J Med 30: 1198-210. 